Received: December 02, 2016 Accepted: December 08, 2016 Published: February 02, 2017

\title{
Lipid Profile of Type 2 Diabetic Patients at a Tertiary Hospital in Tanzania: Cross Sectional Study
}

\author{
Nyasatu G. Chamba ${ }^{1,2}$,Elichilia R Shao ${ }^{1,2,3,4,5, *}$,Tolbert Sonda ${ }^{1,3}$ and Isaack A. Lyarru ${ }^{1,2}$ \\ ${ }^{1}$ Department of Internal medicine Kilimanjaro Christian Medical University College, Tu- \\ maini University, Makumira PO BOX 2240, Moshi Tanzania \\ ${ }^{2}$ Department of Internal Medicine Kilimanjaro Christian Medical Centre, PO BOX 3010 \\ Moshi Tanzania \\ ${ }^{3}$ Kilimanjaro Clinical Research Institute, PO BOX 2236, Moshi Tanzania \\ ${ }^{4}$ Better Human Health Foundation, PO BOX 1348, Moshi Tanzania \\ ${ }^{5}$ Imagedoctors Organization, PO BOX 16341, Arusha Tanzania
}

*Corresponding author: Elichilia R Shao, Department of Internal Medicine Kilimanjaro Christian Medical University College, Tumaini University Makumira, Moshi, Tanzania. Tel: 255784491622; E-mail: elichilia2004@yahoo.co.uk

\section{Abstract}

\subsection{Background}

Patients with diabetes mellitus are at high risk of cardiovascular events because of abnormal lipid status. Dyslipidemia is common in diabetes mellitus and is associated with cardiovascular complications. Early diagnosis and treatment is the main cornerstone in the prevention of its multiple complications. There is scarcity of data on the magnitude and risk factors associated with dyslipidemia among diabetic patients in the Northern zone of Tanzania.

\subsection{Objective}

The aim of the study was to determine the prevalence of abnormal lipid profile levels among patients attending the diabetes clinic at Kilimanjaro Christian Medical Centre, Moshi Tanzania.

\subsection{Methodology}

A cross-sectional study was conducted from October 2012 to March 2013 involving 119 diabetic patients, who were 18 years and above from the diabetes clinic at Kilimanjaro Christian Medical Centre, Moshi.

A structured questionnaire was administered to evaluate the socio-demographic and clinical characteristics. Standard procedures were followed for measuring

blood pressure, body mass index and waist circumference. Fasting blood samples were taken to measure lipid profiles and glycosylated hemoglobin.

Data analysis was done by Statistical Package for Social Science version 21 statistical software and chi-squared test, and multiple logistic regression were used for data analysis and p-value of $<0.05$ was considered to be statistically significant.

\subsection{Results}

The prevalence of dyslipidemia among diabetic patients was $83 \%$. Among the abnormal lipid profile levels, elevated Low Density Lipoprotein Cholesterol constituted the highest single abnormality having $67.23 \%$. Dyslipidemia was mostly seen in the females (88.9\%), advanced age of 50 years and above $(86.7 \%)$, poor glycemic control (glycosylated hemoglobin $>7 \%$ ) was $60.7 \%$ and $\mathrm{BMI}>25 \mathrm{~kg} / \mathrm{m} 2$ was $91.7 \%$. The multivariate logistic regression showed that BMI was the sole determinant for the development of dyslipidemia.

\subsection{Conclusions}

The prevalence of dyslipidemia is high. The sole determinant for diabetic dyslipidemia among our study population was increase in the body mass index. There is an urgent need for effective strategies for primary prevention of obesity, diagnosis and treatment of dyslipidemia among diabetic patients.

1.6 Key words

Lipid profile levels; Dyslipidemia; Diabetes Mellitus; BMI; Tanzania 


\subsection{Abbreviations}

BMI: Body mass index;BP:Blood Pressure;DM:Diabetes Mellitus;FPG:Fasting Plasma Glucose:FFA:Free Fatty Acid;HbA1C:Glycosylated Hemoglobin;HC:Hip Circumference;HDL:High Density Lipoprotein;HDL-C:High Density Lipoprotein Cholesterol;KCMC:Kilimanjaro Christian Medical Centre;LDL:Low Density Lipoprotein;LDL-C:Low Density Lipoprotein Cholesterol;SD LDL :small dense Low Density Lipoprotein;SBP:Systolic Blood Pressure;SPSS:Statistical Package for Social Science;SSA:Sub-Saharan Africa;TC :Total Cholesterol;TG :Triglyceride;VLDL:Very Low ;Density Lipoprotein;WC:Waist Circumferene;WHO :World Health Organization;WHR:Waist hip ratio;WHtR:Waist to height ratio.

\section{Background}

Diabetes Mellitus (DM) is a metabolic disorder due to hyperglycemia, thus having disturbances in carbohydrates, lipid and protein metabolism which results from defects in insulin secretion, insulin action and or both [1]. Globally, diabetes mellitus has been a major health care problem. In sub-Saharan Africa (SSA), diabetes represents $4.2 \%$ of the global population [2] it is estimated that by 2025 , the number will increase by $80 \%$, with a higher prevalence being in the urban areas [2,3].

Dyslipidemia is a disorder which arises as a result of abnormalities in the plasma lipoproteins. The lipid abnormalities in diabetes include quantitative changes which occur due to an increase of glucose for very low density lipoprotein (VLDL) synthesis and decrease in lipoprotein lipase activity leading to decrease of VLDL from peripheral circulation, increase in low density lipoprotein-C (LDL-C) levels and decrease in high density lipoprotein C (HDLC) levels due to increase in hepatic activity decrease in VLDL clearance. Qualitative changes consists of increase of triglyceride (TG), LDL-C and HDL-C, non-enzymatic glycation of LDL and non-enzymatic glycation of high density lipoprotein (HDL) [4].

Due to the abnormalities in lipoproteins, diabetes mellitus is associated with cardiovascular and cerebrovascular morbidity and mortality worldwide [5]. Dyslipidemia affects approximately $70 \%$ to $97 \%$ of people with diabetes [6]. World Health Organization (WHO) in 2002 reported that dyslipidemia accounted for $18 \%$ of ischemic heart disease, $56 \%$ of stroke and over 4 million deaths per year globally [7].

The prevalence of dyslipidemia is terrifyingly high within the African continent. The trend has been seen to increase, in Nigeria, the prevalence ranged from $82.6 \%$ to $90.7 \%$ from 2008 to 2011 respectively $[8,9,10]$. In South Africa the prevalence is over 90\% [11]. In Tanzania, the prevalence of diabetic dyslipidemia was $95 \%$ in 2007 [12]. This is mainly due to the adopted western diet, sedentary lifestyle as well as physical inactivity resulting to obesity [13]. By determining the prevalence of abnormal lipid profile levels among the diabetic patients, it will provide the need to aggressively manage dyslipidemia among diabetic patients.

\section{Patients and Methods}

A cross-sectional study was carried out at KCMC, Moshi Tanzania from October 2012 to March 2013. The study participants included all DM patients who were consecutively recruited, aged 18 years and above receiving treatment at the KCMC diabetic clinic during the study period. Patients on lipid lowering agents, pregnant women, HIV/AIDS on treatment and those with renal failure were excluded. Relevant medical history was completed and physical examination was conducted on all subjects who had an overnight fast for at least 8 hours. Ethical clearance was secured from Kilimanjaro Christian Medical University College (KCMUCo) Ethical Committee and signed consent to take part in the research and to publish results was obtained from the participants.

Anthropometric measurements, including weight, height and waist circumference were measured with the subjects wearing light clothing and no shoes. Body Mass Index $\left(\mathrm{kg} / \mathrm{m}^{2}\right)$ was calculated as weight (kilograms) divided by squared height in (meters). The study populations were classified as underweight BMI $<18.5 \mathrm{~kg} / \mathrm{m} 2$, normal BMI $18.5 \geq$;BMI $<25 \mathrm{~kg} / \mathrm{m}^{2}$ and overweight $\mathrm{BMI} \geq ; 25 \mathrm{~kg} / \mathrm{m}^{2}$ and obese $\mathrm{BMI} \geq ; 30 \mathrm{~kg} / \mathrm{m} 2$ [14].Central obesity was considered as measurements above $102 \mathrm{~cm}$ and $88 \mathrm{~cm}$ in men and women respectively. Blood pressure was measured twice for each patient after at least 5 minutes of rest, by the use of a standardized mercury sphygmomanometer. Glycosylated hemoglobin test was done on the spot using the A1CNOW PLUS kits from the Bayer manufacturer and the results were ready in 5 minutes. Poor glycemic control was defined as glycosylated hemoglobin as $>7 \%$.

After an overnight fast, approximately $4 \mathrm{mls}$ of venous blood was obtained from each patient for lipid profile (TC, TG, LDL-C and HDL-C) analysis. The samples were analyzed using the chemical analyzer COBAS INTEGRA 400 Plus serial NO 397672 in the main Kilimanjaro Christian Medical Centre (KCMC) laboratory. Dyslipidemia was taken as derangement in any of the lipid components: TC $>5.2 \mathrm{mmol} / 1$, LDL-C $>2.6 \mathrm{mmol} / 1$, HDL-C $<1.1 \mathrm{mmol} / \mathrm{l}$ for males, $<1.38 \mathrm{mmol} / \mathrm{l}$ for females and TG $>1.7 \mathrm{mmol} / \mathrm{l}$ [15].Data analysis was done using Statistical Package of Social Sciences (SPSS) version16. Analysis of variance (ANOVA), t-test and chi-square test were used. Regression analysis was used to determine the predictors of dyslipidemia. A 95\% confidence was used for the determination of significance of probabilities, and p-value $<0.05$ was regarded as statistically significant. Patients had to sign the consent form before enrolled in the study. Those found with dyslipidemia were started on lipid lowering agents and advised on the lifestyle changes. Original data and supporting material are available upon request from the publishers.

\section{Results}

A total of 119 patients with diabetes mellitus type 2 were included in the study. Sixty $(50.42 \%)$ patients were males. The mean ( \pm SD, range) age was $58.1( \pm 12.2,27-83)$ years. Eighty-six 
(63.7\%), were in the range of 50-70 years. Duration of diabetes ranged from 2 months to 28 years with mean $( \pm S D)$ duration of $9.4( \pm 6.6)$ years. More than half of the patients $91(76.47 \%)$ had diabetes for more than 5 years and 28(23.53\%) for up to 5 years. Ninety-six (80.67\%) had poor glycemic control HbA1C >7\%, Good compliance with treatment was reported among 87 (73\%) of the patients.

Of the 119 diabetic patients, 78 (65.55\%) were hypertensive and in Eleven (9.2\%) patients reported to be smokers and alcohol intake was significant in $34(28.57 \%)$ of the patients.

The body mass index (BMI) ranged from 18.8- 45.1 with mean $( \pm$ SD) of $27.9( \pm 5.0)$. About $31(26 \%)$ of the patients had a normal BMI, 56(47\%) were overweight and 32(27\%) were obese. Among the females, the BMI ranged from18.8- 45.1 with mean $( \pm \mathrm{SD})$ of $29.4( \pm 5.5)$, and in males, the BMI ranged from19.335.5 with mean $( \pm S D)$ of 26 ( \pm 3.8 ).-Majority of the patients 85 $(63.0 \%)$ were physically inactive. Among the 119 patients, 86 $(63.7 \%)$ were on oral hypoglycemic drugs, 34 (25.2\%) on insulin only, $9(6.7 \%)$ both insulin and oral hypoglycemic drugs while only 6 (4.4\%) were on diet control (Table 1$)$.

Diabetic dyslipidemia was found in $(94.1 \%)$ patients. The pattern of lipid abnormalities according to sex, age, BMI and central obesity are presented in (Table 2). High TG, high LDL-C, high TC and low HDL-C exhibited an increasing trend in the proportion of patients with dyslipidemia by the BMI and the differences were statistically significant $(\mathrm{p}<0.05)$. A similar trend was observed in the patients with central obesity compared to those without. The difference was statistically significant for high TC and low HDL-C and the overall dyslipidemia $(\mathrm{p}<0.05)$.

The following risk factors namely female sex, age above 50years, BMI (overweight and obese), poor glycemic control, central obesity and physical inactivity were associated with diabetic dyslipidemia among diabetic patients attending the diabetes clinic, the p-values were statistically significant (Table 3 ). Other variables namely duration of diabetes mellitus, the type of diabetes mellitus, smoking habits and hypertension were not statistically significant in the association of dyslipidemia.

By multivariate logistic regression analysis, significant predictor for dyslipidemia among the diabetic patients was overweight and obesity (BMI $>25 \mathrm{~kg} / \mathrm{m}^{2}$ ), with p-value of 0.040 , OR (95\%CI) 0.2 (0.1-0.9).

\section{Discussion}

The overall prevalence of diabetic dyslipidemia in this study was found to be $83.0 \%$. The prevalence is similarly high compared to the study done by Chattanda in Dar es Salaam, Tanzania where the prevalence was found to be 95\% [12]. Though for the past five years, the prevalence of diabetic dyslipidemia seems to be gradually declining, it is still quite high. The apparent decline can be explained by the interventions in which the Ministry
Table 1 Socio-demographic and clinical characteristics among diabetic type II patients attending KCMC clinic from October 2012 to March 2013 $(n=119)$

\begin{tabular}{|c|c|c|}
\hline Variable & Attribute & No.(\%) \\
\hline \multirow[t]{2}{*}{ Sex } & Females & $\begin{array}{c}59 \\
(49.6)\end{array}$ \\
\hline & Males & $\begin{array}{c}60 \\
(50.4)\end{array}$ \\
\hline \multirow[t]{6}{*}{$\begin{array}{c}\text { Age } \\
\text { (years): }\end{array}$} & $\begin{array}{c}\text { Mean } \\
( \pm \mathrm{SD}, \text { range })\end{array}$ & $\begin{array}{c}58.1 \\
( \pm 12.2,27-83)\end{array}$ \\
\hline & Females & $\begin{array}{c}54.3 \\
( \pm 13.1,27-83)\end{array}$ \\
\hline & Males & $\begin{array}{c}62.4 \\
( \pm 9.6,35-79)\end{array}$ \\
\hline & $\begin{array}{l}\text { Younger } \\
\text { than } 50\end{array}$ & $\begin{array}{c}30 \\
(22.2)\end{array}$ \\
\hline & $50-70$ & $\begin{array}{c}86 \\
(63.7)\end{array}$ \\
\hline & Older than 70 & $\begin{array}{c}19 \\
(14.1)\end{array}$ \\
\hline Type II DM & Type II & $\begin{array}{c}119 \\
(88.1)\end{array}$ \\
\hline \multirow[t]{3}{*}{$\begin{array}{c}\text { Duration } \\
\text { of DM (years) }\end{array}$} & Mean (SD, range) & $\begin{array}{c}9.4 \\
(6.6,0-28)\end{array}$ \\
\hline & Up to 5 & $\begin{array}{c}44 \\
(32.6)\end{array}$ \\
\hline & More than 5 & $\begin{array}{c}91 \\
(67.4)\end{array}$ \\
\hline \multirow[t]{2}{*}{$\begin{array}{l}\text { Glycemic } \\
\text { control }\end{array}$} & Good $<7 \%$ & $\begin{array}{c}53 \\
(39.3)\end{array}$ \\
\hline & Poor $>7 \%$ & $\begin{array}{c}82 \\
(60.7) \\
\end{array}$ \\
\hline \multirow[t]{2}{*}{$\begin{array}{l}\text { Compliance } \\
\text { on } \\
\text { treatment }\end{array}$} & Good & $\begin{array}{l}77 \\
(65)\end{array}$ \\
\hline & Poor & $\begin{array}{c}42 \\
(35)\end{array}$ \\
\hline Hypertension & Yes & $\begin{array}{c}78 \\
(65.5)\end{array}$ \\
\hline Smoking & Yes & $\begin{array}{c}11 \\
(9.2)\end{array}$ \\
\hline $\begin{array}{l}\text { Alcohol } \\
\text { Intake }\end{array}$ & Yes & $\begin{array}{c}34 \\
(28.6)\end{array}$ \\
\hline \multirow[t]{4}{*}{$\begin{array}{l}\text { Body Mass } \\
\text { Index } \\
\left(\mathrm{kg} / \mathrm{m}^{2}\right)\end{array}$} & $\begin{array}{c}\text { Mean } \\
( \pm \text { SD,Range) }\end{array}$ & $\begin{array}{c}27.9 \\
( \pm 5.0,18.8-45.1)\end{array}$ \\
\hline & $18.5-24.9$ & $\begin{array}{c}31 \\
(26)\end{array}$ \\
\hline & $25.0-29.9$ & $\begin{array}{l}56 \\
(47)\end{array}$ \\
\hline & 30 or above & $\begin{array}{c}32 \\
(27)\end{array}$ \\
\hline \multirow[t]{2}{*}{ Physical activity } & Inactive & $\begin{array}{c}85 \\
(71.43 .)\end{array}$ \\
\hline & Active & $\begin{array}{c}34 \\
(28.57)\end{array}$ \\
\hline
\end{tabular}


Table 2: The pattern of lipid abnormalities in sex, age, BMI and central obesity among type II diabetic patients attending KCMC diabetes clinic from October 2012 to March 2013, $(n=119)$

\begin{tabular}{|c|c|c|c|c|c|c|}
\hline \multirow[t]{2}{*}{ Variable } & \multirow[t]{2}{*}{ Total } & High TG & High LDL & High TC & Low HDL & Overall \\
\hline & & $\begin{array}{l}\text { No. } \\
(\%)\end{array}$ & $\begin{array}{l}\text { No. } \\
(\%)\end{array}$ & $\begin{array}{l}\text { No. } \\
(\%)\end{array}$ & $\begin{array}{l}\text { No. } \\
(\%)\end{array}$ & $\begin{array}{l}\text { No. } \\
(\%)\end{array}$ \\
\hline \multicolumn{7}{|c|}{ Sex } \\
\hline Female & 59 & $\begin{array}{c}34 \\
(47.2)\end{array}$ & $\begin{array}{c}52 \\
(72.2)\end{array}$ & $\begin{array}{c}36 \\
(56.2)\end{array}$ & $\begin{array}{c}41 \\
(70.8)\end{array}$ & $\begin{array}{c}64 \\
(88.9)\end{array}$ \\
\hline Male & 60 & $\begin{array}{c}30 \\
(47.6)\end{array}$ & $\begin{array}{c}34 \\
(54.0)\end{array}$ & $\begin{array}{c}23 \\
(47.9)\end{array}$ & $\begin{array}{c}34 \\
(63.9)\end{array}$ & $\begin{array}{c}48 \\
(76.2)\end{array}$ \\
\hline p-value & & 0.963 & 0.028 & 0.382 & 0.728 & 0.05 \\
\hline \multicolumn{7}{|c|}{ Age (years) } \\
\hline$<50$ & 22 & $\begin{array}{c}12 \\
(40.0)\end{array}$ & $\begin{array}{c}14 \\
(46.7)\end{array}$ & $\begin{array}{c}9 \\
(30.0)\end{array}$ & $\begin{array}{c}15 \\
(50.0)\end{array}$ & $\begin{array}{c}21 \\
(70.0)\end{array}$ \\
\hline 50 or older & 97 & $\begin{array}{c}52 \\
(49.5)\end{array}$ & $\begin{array}{c}72 \\
(68.6)\end{array}$ & $\begin{array}{c}50 \\
(47.6)\end{array}$ & $\begin{array}{c}60 \\
(57.1)\end{array}$ & $\begin{array}{c}91 \\
(86.7)\end{array}$ \\
\hline p-value & & 0.357 & 0.028 & 0.086 & 0.487 & 0.032 \\
\hline \multicolumn{7}{|c|}{ Body mass index $\left(\mathrm{kg} / \mathrm{m}^{2}\right)$} \\
\hline Normal & 31 & $\begin{array}{c}12 \\
(30.8)\end{array}$ & $\begin{array}{c}13 \\
(33.3)\end{array}$ & $\begin{array}{c}10 \\
(25.6)\end{array}$ & $\begin{array}{c}13 \\
(33.3)\end{array}$ & $\begin{array}{c}24 \\
(61.5)\end{array}$ \\
\hline Overweight/obese & 88 & $\begin{array}{c}52 \\
(54.2)\end{array}$ & $\begin{array}{c}73 \\
(76.0)\end{array}$ & $\begin{array}{c}49 \\
(51.0)\end{array}$ & $\begin{array}{c}62 \\
(64.6)\end{array}$ & $\begin{array}{c}88 \\
(91.7)\end{array}$ \\
\hline p-value & & 0.014 & $<0.001$ & 0.007 & 0.001 & $<0.001$ \\
\hline \multicolumn{7}{|c|}{ Waist circumference } \\
\hline Central obesity & 68 & $\begin{array}{c}41 \\
(53.9) \\
\end{array}$ & $\begin{array}{c}54 \\
(71.1) \\
\end{array}$ & $\begin{array}{c}39 \\
(51.3) \\
\end{array}$ & $\begin{array}{c}52 \\
(68.4) \\
\end{array}$ & $\begin{array}{c}70 \\
(92.1)\end{array}$ \\
\hline No central obesity & 51 & $\begin{array}{c}23 \\
(39.0)\end{array}$ & $\begin{array}{c}32 \\
(55.9)\end{array}$ & $\begin{array}{c}20 \\
(33.9)\end{array}$ & $\begin{array}{c}23 \\
(39.0)\end{array}$ & $\begin{array}{c}42 \\
(71.2)\end{array}$ \\
\hline p-value & & 0.084 & 0.069 & 0.043 & 0.001 & 0.001 \\
\hline
\end{tabular}

Table 3: Dyslipidemia associated risk factors among type II diabetic patients attendingKCMC diabetes clinic from October 2012 to March $2013(n=119)$

\begin{tabular}{|c|c|c|c|c|}
\hline \multirow{2}{*}{ Variable } & \multicolumn{2}{|c|}{$\begin{array}{c}\text { Univariate } \\
\text { analysis }\end{array}$} & \multicolumn{2}{c|}{$\begin{array}{c}\text { Multivariate } \\
\text { analysis }\end{array}$} \\
\hline & $\begin{array}{c}\text { OR } \\
(95 \% \mathrm{CI})\end{array}$ & $\mathrm{p}$-value & $\begin{array}{c}\text { OR } \\
(95 \% \mathrm{CI})\end{array}$ & $\mathrm{p}$-value \\
\hline Sex: & $\begin{array}{c}0.4 \\
(0.2-1.0)\end{array}$ & 0.05 & $\begin{array}{c}0.4 \\
(0.1-1.7)\end{array}$ & 0.233 \\
\hline $\begin{array}{c}0.4 \\
\text { Age } \\
\text { (years): }\end{array}$ & $0.1-1.0)$ & 0.032 & $\begin{array}{c}0.5 \\
(0.1-2.2)\end{array}$ & 0.326 \\
\hline $\begin{array}{c}\text { Body mass index } \\
(\mathrm{kg} / \mathrm{m} 2)\end{array}$ & $\begin{array}{c}0.1 \\
(0.1-0.4)\end{array}$ & $<0.001$ & $\begin{array}{c}0.2 \\
(0.1-0.9)\end{array}$ & 0.04 \\
\hline $\begin{array}{c}\text { Glycemic } \\
\text { control }\end{array}$ & $\begin{array}{c}3.0 \\
(1.2-7.3)\end{array}$ & 0.02 & $\begin{array}{c}1.0 \\
(0.2-3.6)\end{array}$ & 0.927 \\
\hline $\begin{array}{c}0.2 \\
\text { Waist } \\
\text { Circumference }\end{array}$ & $0.1-1.0)$ & 0.001 & $\begin{array}{c}0.1 \\
(0.2-2.5)\end{array}$ & 0.525 \\
\hline Physical activity & $\begin{array}{c}3.3 \\
(1.1-10.4)\end{array}$ & 0.032 & $\begin{array}{c}1.0 \\
(0.2-3.2)\end{array}$ & 0.695 \\
\hline
\end{tabular}

of Health has set in the prevention of most non-communicable diseases, diabetes mellitus being one of them. The Tanzania diabetes association has set strategies in addressing the extent of the problem and in educating the patients on the importance of strict diabetic diet, drug adherence and physical activities thus; it has been noticed that there is an increased awareness of the problem. The lipid profile tests are now readily available for an early diagnosis of dyslipidemia in which case early interventions are done without delay. Comparable study also done by Mwita in Dar es Salaam in 2009, the prevalence of dyslipidemia among the diabetic patients was $88 \%$ [16]. Within the African continent, similar studies have revealed high prevalence of dyslipidemia among diabetic patients; in Nigeria $82.6 \%$ to 90.7\% from 2008-2011 respectively [8, 9, 10] and in South Africa [11]. Other areas such as Tehran and USA, similarly high prevalence of dyslipidemia was also observed $88.9 \%$ and $97 \%$ respectively $[17,18]$. The fairly high prevalence in this study may be attributed to the current trend towards urbanization and adoption to the western diet and lifestyle which was also reported by Njelekela et al [13].

This study showed a high prevalence of dyslipidemia with the commonest lipid abnormality being elevated LDL-C (64\%) 
followed by low HDL-C (56\%). Similar findings were also noted in the Third US National Health and Nutritional Examination Survey and the Behavioral Risk factors Surveillance System where majority DM patients had LDL-C of 58\% [19] in Gaborone [20] and in Ghana [21]. Reasoning to this is that within the African ethnicity, African-Americans, it has been observed that the elevated LDL-C levels are a common subclass of dyslipidemia compared with other subclasses [16].

Different observations from other studies where total cholesterol to be the common subclass in dyslipidemia. In Dar es Salaam, Chattanda observed that among the subclasses of dyslipidemia, $95 \%$ had high triglycerides [12]. In Kenya, over $70 \%$ of the study participants had high total cholesterol levels [22] as well as in Jordan [23]. The observed differences in the subclasses of dyslipidemia could be explained by the difference in ethnicity where Indians who tend to have elevated levels of total cholesterol, presented in the diabetic clinics. Majority of Indians reside in the urban regions within the big cities in Africa. In this case, the different cut off levels in classifying dyslipidemia could have also contributed to the difference. The high frequency of LDL-C among the female patients over 50 years, was over $90 \%$ in this study. It can be explained by the fact that over half of the women involved in our study were in the post-menopausal years who tend to lose the protective effect of estrogen on lipid metabolism. Thus this leads to higher prevalence of LDL-C in women compared to men, also mostly observed within the black race. On the other hand, Chattanda did not find any difference between males and females [12]; this could have been due to similar lifestyles in the study population and the racial differences. This is comparable to a study done in Pakistan, where they found that females above 60 years were more likely to have dyslipidemia [24].

The increase in BMI $\left(\geq ; 25.0 \mathrm{~kg} / \mathrm{m}^{2}\right)$ was an independent determinant of dyslipidemia among the diabetic patients in this study, which was strongly associated with the prevalence of dyslipidemia. Majority of the patients also had central obesity over 90\%. Similarly in Gaborone [20] and South-East Nigeria [10] showed that overweight and obesity was strongly associated with elevated plasma lipid levels. A report in the National Health and Nutrition Examination Survey, 1999-2004, showed that the prevalence of dyslipidemia substantially increases with increased BMI [14]. Despite the gender differences within our study population, it was clearly seen that an increase in BMI among diabetic patients is the strongest factor in the development of dyslipidemia. Physical inactivity mostly observed among the elderly patients due to arthritis could be another contributory factor of overweight and obesity as well. In contrast to the study done in Dar es Salaam, where poor glycemic control was the sole determinant leading to the development of dyslipidemia [12]. The difference could be explained by the fact that most of the diabetic patients were on medications, mostly oral hypoglycemic drugs, majority having a good compliance henceforth, such treatment reduces the blood glucose level and most probably alters the overall diabetic dyslipidemia pathophysiology.

\section{Conclusion}

Increased BMI was the strongest determinant as it was found to be the sole associated risk factor on the high prevalence of dyslipidemia which is over $83.0 \%$ and the commonest dyslipidemia was elevated LDL-C.

\section{Acknowledgement}

The authors are grateful to the patients' participation in this study.

\subsection{Authors' Contributions}

NGC and IAL were involved in designing the study, drafting the proposal, data collection, analysis and writing up the first draft of the manuscript. ERS and TS reviewed and re-analyzed the dataset and reviewed the manuscript and references to get the final version. All authors agreed with the final format of the manuscript for publication.

\section{References}

1. American Diabetes Association. Diagnosis and classification of diabetes mellitus. Diabetes care. 2005; 28(Suppl1): S37-42.

2. International Diabetes Federation. The Diabetes Declaration and Strategy for Africa; 2006.

3. Kengne AP, Amoah AGB, Mbanya JC. Cardiovascular complications of Diabetes Mellitus in Sub-Saharan Africa. Circulation. 2005;112(23):3592-3601.

4. Arora M, Koley S, Gupta S , Sandhul JS. A Study on Lipid Profile and Body Fat in Patients with Diabetes Mellitus. Punjab, India. Anthropologist, 2007;9(4):295-298.

5. Gadi R, Samaha F.F. Dyslipidemia in type 2 diabetes mellitus. Current Diabetes Reports. 2007;7(3):228-234.

6. Ansorge R. Managing high triglycerides, cholesterol in diabetes. Lowering cholesterol is very important in diabetes. About.com.updated 10.11.2008.

7. The WHO Report. Quantifying selected major risks to health. Reducing risks, promoting healthy life. Geneva: WHO; 2002. Chap 4: P.47-97.

8. Ogbera A, Fasanmade O, Chinenye S, Akinlade A. Characterization of Lipid parameters in Diabetes Mellitus- a Nigerian report. International archives of medicine. 2009;2:19.

9. Okafor CI, Fasanmade OA, Oke DA. Pattern of dyslipidemia among Nigerians with type 2 diabetes mellitus. Nigeria $\mathrm{J}$ Clin Pract. 2008;11(1):25-31.

10. Jisieike-Onuigbo NN, Unuigbe ET, Oguejioofor CO. Dyslipidemias in Type 2 diabetes mellitus patients in Nnewi South-East Nigeria. Ann Afr. Med. 2011;10(4):285-289. 
11. Vezi ZB and Naidoo DP. Dyslipidemia among black patients with type 2 diabetes. Cardiovascular Journal South African. 2005;16(4):194-198.

12. Chattanda, S.P and Mgonda Y.M. Diabetic dyslipidemia among diabetic patients attending specialized clinics in Dar es Salaam. Tanzania Medical Journal. 2008; 23(1):08-11.

13. Njeleka MA, Negishi $H$, Nara $Y$, Sato $T$, Tomohiro $M$, Kuga S, et al. Obesity and Lipid profiles in middle aged men and women in Tanzania. East Afr. Med J. 2002;79(2):58-64.

14. Obesity education Initiative. Clinical Guidelines on the Identification, Evaluation and Treatment of Overweight and Obesity in Adults. National Institute of Health Publication 1998.

15. Scott MG, James K, Cleeman, Noel BM et al., Implication of Recent clinical Trials for the National Cholesterol Education Program Adult Treatment Panel III Guidelines Circulation 2004;110(2):227-239.

16. Mwita JC, Mugusi F, Lwakatare J and Chiwanga F. Hypertension control and other cardiovascular risk factors among diabetic patients at Muhimbili National Hospital, Tanzania. East African Journal of Public Health. 2012; 9(2).

17. Ghoddusi K, Ameli J, Kachuee H, Pourfarziani V, Saadat A, Karami Q. Association of diabetes mellitus and dyslipidaemias in the Tehran population. Eastern Mediterranean Health Journal $14 ; 2008$.
18. Fagot-Campagne A, Rolka DB, Beckles GL, Gregg EW, Narayan KM. Prevalence of lipid abnormalities, awareness, and treatment in U.S. adults with diabetes. Diabetes 2000;318:49.

19. Saaddine JB, Engelgau MM, Beckles GL, Gregg EW, Thompson TJ, Narayan KM, A diabetes report card for the United States: quality of care in the 1990s. Ann Intern Med. 2002;136(8): 565-574.

20. Mengesha, AY. Lipid profile among diabetes patients in Gaborone, Botswana. South Africa Med. J. 2006;96:147-148.

21. Eghan BA Jr., Acheampong JW. Dyslipidemia in outpatients at General Hospital in Kumasi, Ghana. Croat Med J. 2003;44(5):576-578.

22. Otieno CF, Mwendwa FW, Vaghela V, Ogola EN, Amayo EO. Lipid Profile of Ambulatory Patients with Type 2 Diabetes Mellitus at Kenyatta National Hospital, Nairobi. East Afr Med J. 2005; 82(12Suppl):S173-179.

23. Khader SY. Batieha A, El-Khateeb M, Al Omari M, Ajlouni K. Prevalence of dyslipidemia and its associated factors among Jordanian adults; Journal of clinicallipidology. (2010);4(1):53-58.

24. Humayum A, Shah SA, Alam S, Hussein H. Relationship of Body Mass Index and Dyslipidemia in Different Age Groups of Male and Female Population of Peshawar. J. Ayub Med Coll. Abbottabad 2009;21(2). 